\title{
Supplementary stabilizer design based on STATCOM
}

\author{
Reza Hemmati, Sayed Mojtaba Shirvani Boroujeni, Elahe Behzadipour and Hamideh Delafkar
}

Department of Electrical Engineering, Boroujen Branch, Islamic Azad University, Boroujen, Iran

Iranreza.hematti@gmail.com,mo_shirvani@yahoo.com, E.behzadipour@yahoo.com, delafkar@aut.ac.ir

\begin{abstract}
This paper presents the application of static synchronous compensator (STATCOM) to enhance damping of Low Frequency Oscillations at a single-machine infinite-bus power system installed with a STATCOM as cast study. STATCOM is considered in order to damping of Low Frequency Oscillations. Therefore, the supplementary stabilizer based STATCOM (like power system stabilizer) is designed to reach defined purpose. Optimization methods such as Particle Swarm Optimization (PSO) and Genetic Algorithms (GA) are considered to design STATCOM supplementary stabilizer controller. To show effectiveness and also comparing these two methods, the proposed methods are simulated under different operating conditions. Several linear time-domain simulation tests visibly show the validity of proposed methods in damping of power system oscillations. Also simulation results emphasis on the better performance of PSO in comparison with GA method.
\end{abstract}

Keywords: Static Synchronous Compensator, Particle Swarm Optimization, Genetic Algorithms, Power Stabilizer.

Introduction

The rapid development of the high-power electronics industry has made Flexible AC Transmission System (FACTS) devices viable and attractive for utility applications. FACTS devices have been shown to be effective in controlling power flow and damping power system oscillations. In recent years, new types of FACTS devices have been investigated that may be used to increase power system operation flexibility and controllability, to enhance system stability and to achieve better utilization of existing power systems (Hingorani et al., 2000). The static synchronous compensator (STATCOM) is one of the most important FACTS devices and it is based on the principle that a voltage-source inverter generates a controllable AC voltage source behind a transformer-leakage reactance so that the voltage difference across the reactance produces active and reactive power exchange between the STATCOM and the transmission network. The STATCOM is one of the important 'FACTS' devices and can be used for dynamic compensation of power systems to provide voltage support and stability improvement (Gyugyi, 1979; Gyugyi et al., 1990; Mori et al., 1993; Schauder et al., 1993; Trainner et al., 1994; Ekanayake et al., 1995; Schauder et al., 1995; Ainsworth et al., 1998; SaadSaoud et al., 1998;). A unified Phillips-Heffron model (Heffron et al., 1952) of power systems installed with a STATCOM has been established by Wang et al. (1999). STATCOM has been developed from a switch mode voltage-source converter configuration with an energystorage device (DC capacitor). Also, the STATCOM can be used for voltage support and transient stability improvement by damping of low frequency power system oscillations. Low frequency oscillations (LFO) in electric power system occur frequently due to disturbances such as changes in loading conditions or a loss of a transmission line or a generating unit. These oscillations need to be controlled to maintain system stability. In past decades power system stabilizer or PSS was applied for damping power system oscillations. Recently new power system controllers like as FACTS devices are presented as power system stabilizer. Many in the past have presented lead-Lag type UPFC stabilizers (Tambey et al., 2003). They are designed for a specific operating condition using linearized models. More advanced control schemes such as self-tuning control (Cheng et al., 1986), Particle-Swarm method (Al-Awami et al., 2007) and fuzzy logic control (Mishra et al., 2000; Eldamaty et al., 2005) offer better dynamic performances than fixed parameter controllers. Fuzzy control design is attractive because it does not require a mathematical model of the system under study and it can cover a wide range of operating conditions and is simple to implement.

The objective of this paper is to investigate the ability of optimization methods such as Genetic Algorithms (GA) and Particle Swarm Optimization (PSO) for STATCOM supplementary stabilizer design. A Sigel Machine Infinite Bus (SMIB) power system installed with a STATCOM is considered as case study and a STATCOM based stabilizer controller whose parameters are tuned using PSO and GA is considered as power system stabilizer. Different load conditions are considered to show effectiveness of the proposed methods and also comparing the performance of these two methods. Simulation results show the validity of proposed methods in LFO damping.

\section{Illustrative test}

Fig. 1 shows the case study system in this paper. The system is a Single Machine Infinite Bus (SMIB) power system with STATCOM installed.
Research article

CIndian Society for Education and Environment (iSee)
"Stabilizer design based on STATCOM" http://www.indjst.org
Reza Hemmati et al. Indian J.Sci.Technol. 
Fig. 1. A single-machine infinite-bus power system

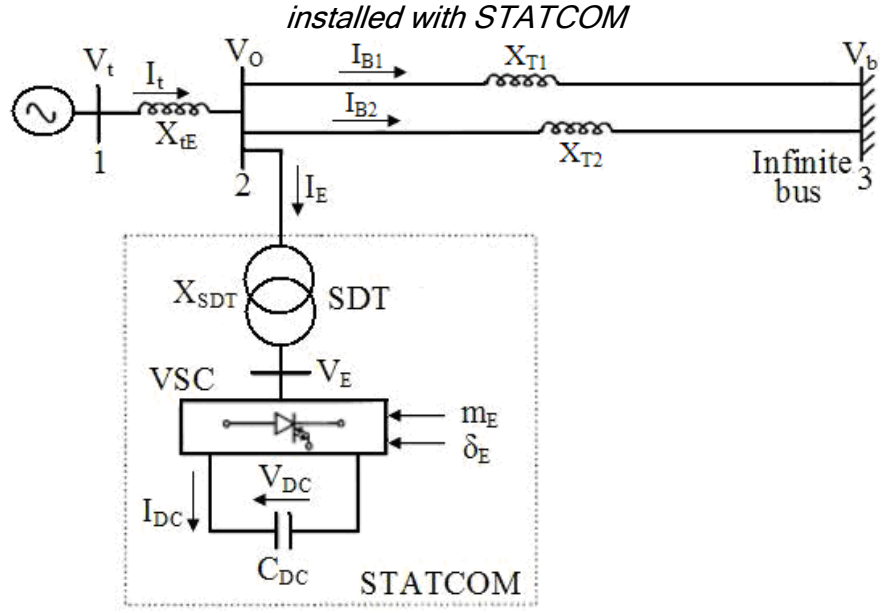

\section{System modeling}

\section{Nonlinear model}

A non-linear dynamic model of the system is derived by disregarding the resistances of all components of the system (generator, transformer, transmission line and shunt converter transformer) and the transients of the transmission lines and transformer of the STATCOM. The nonlinear dynamic model is given as below (1) (Wang et al., 1999).

$$
\left\{\begin{array}{l}
\dot{\omega}=\left(\mathrm{P}_{\mathrm{m}}-\mathrm{P}_{\mathrm{e}}-\mathrm{D} \omega\right) / \mathrm{M} \\
\dot{\delta}=\omega_{0}(\omega-1) \\
\dot{\mathrm{E}_{\mathrm{q}}^{\prime}}=\left(-\mathrm{E}_{\mathrm{q}}+\mathrm{E}_{\mathrm{fd}}\right) / \mathrm{T}_{\mathrm{do}}^{\prime} \\
\dot{\mathrm{E}_{\mathrm{fd}}}=\left(-\mathrm{E}_{\mathrm{fd}}+\mathrm{K}_{\mathrm{a}}\left(\mathrm{V}_{\mathrm{ref}}-\mathrm{V}_{\mathrm{t}}\right)\right) / \mathrm{T}_{\mathrm{a}} \\
\dot{\mathrm{V}}_{\mathrm{dc}}=\frac{3 \mathrm{~m}_{\mathrm{E}}}{4 \mathrm{C}_{\mathrm{dc}}}\left(\sin \left(\delta_{\mathrm{E}}\right) \mathrm{I}_{\mathrm{Ed}}+\cos \left(\delta_{\mathrm{E}}\right) \mathrm{I}_{\mathrm{Eq}}\right)
\end{array}\right.
$$

\section{Linear model}

A linear dynamic model is obtained by linearising the non-linear model around nominal operating condition. The linearised model is given as (2).

$$
\left\{\begin{array}{l}
\Delta \dot{\delta}=\mathrm{W}_{0} \Delta \mathrm{W} \\
\Delta \dot{\omega}=\left(-\Delta \mathrm{P}_{\mathrm{e}}-\mathrm{D} \Delta \omega\right) / \mathrm{M} \\
\Delta \dot{\mathrm{E}}_{\mathrm{q}}^{\prime}=\left(-\Delta \mathrm{E}_{\mathrm{q}}+\Delta \mathrm{E}_{\mathrm{fd}}\right) / \mathrm{T}_{\mathrm{do}}^{\prime} \\
\Delta \dot{\mathrm{E}}_{\mathrm{fd}}=-\left(1 / \mathrm{T}_{\mathrm{A}}\right) \Delta \mathrm{E}_{\mathrm{fd}}-\left(\mathrm{K}_{\mathrm{A}} / \mathrm{T}_{\mathrm{A}}\right) \Delta \mathrm{V}_{\mathrm{t}} \\
\Delta \dot{\mathrm{V}}_{\mathrm{dc}}=\mathrm{K}_{7} \Delta \delta+\mathrm{K}_{8} \Delta \mathrm{E}_{\mathrm{q}}^{\prime}-\mathrm{K}_{9} \Delta \mathrm{V}_{\mathrm{dc}}+\mathrm{K}_{\mathrm{ce}} \Delta \mathrm{m}_{\mathrm{E}}+\mathrm{K}_{\mathrm{c} \delta \mathrm{e}} \Delta \delta_{\mathrm{E}}
\end{array}\right.
$$

$$
\begin{aligned}
& \Delta \mathrm{P}_{\mathrm{e}}=\mathrm{K}_{1} \Delta \delta+\mathrm{K}_{2} \Delta \mathrm{E}_{\mathrm{q}}^{\prime}+\mathrm{K}_{\mathrm{pd}} \Delta \mathrm{v}_{\mathrm{dc}}+\mathrm{K}_{\mathrm{pe}} \Delta \mathrm{m}_{\mathrm{E}}+\mathrm{K}_{\mathrm{p} \delta \mathrm{E}} \Delta \delta_{\mathrm{E}} \\
& \Delta \mathrm{E}_{\mathrm{q}}=\mathrm{K}_{4} \Delta \delta+\mathrm{K}_{3} \Delta \mathrm{E}_{\mathrm{q}}^{\prime}+\mathrm{K}_{\mathrm{qd}} \Delta \mathrm{v}_{\mathrm{dc}}+\mathrm{K}_{\mathrm{qe}} \Delta \mathrm{m}_{\mathrm{E}}+\mathrm{K}_{\mathrm{q} \delta \mathrm{E}} \Delta \delta_{\mathrm{E}} \\
& \Delta \mathrm{V}_{\mathrm{t}}=\mathrm{K}_{5} \Delta \delta+\mathrm{K}_{6} \Delta \mathrm{E}_{\mathrm{q}}^{\prime}+\mathrm{K}_{\mathrm{vd}} \Delta \mathrm{v}_{\mathrm{dc}}+\mathrm{K}_{\mathrm{ve}} \Delta \mathrm{m}_{\mathrm{E}}+\mathrm{K}_{\mathrm{v} \delta \mathrm{E}} \Delta \delta_{\mathrm{E}}
\end{aligned}
$$

Fig.2 shows the transfer function model of the system including STATCOM. The model has constant parameters which are denoted by $\mathrm{K}_{\mathrm{ij}}$. These constant parameters are function of the system parameters and the initial operating condition. The control vector $U$ in Fig. 2 is defined as (3).

$$
\mathrm{U}=\left[\begin{array}{ll}
\Delta \mathrm{m}_{\mathrm{E}} & \Delta \delta_{\mathrm{E}}
\end{array}\right]^{\mathrm{T}}
$$

Where:

$\Delta m_{E}$ : Deviation in pulse width modulation index $m_{E}$ of shunt inverter. By controlling $\mathrm{m}_{\mathrm{E}}$, the output voltage of the shunt converter is controlled.

$\Delta \delta_{\mathrm{E}}$ : Deviation in phase angle of the shunt inverter voltage. By controlling $\delta_{\mathrm{E}}$, exchanging active power

Fig. 2. Transfer function model of the system including STATCOM

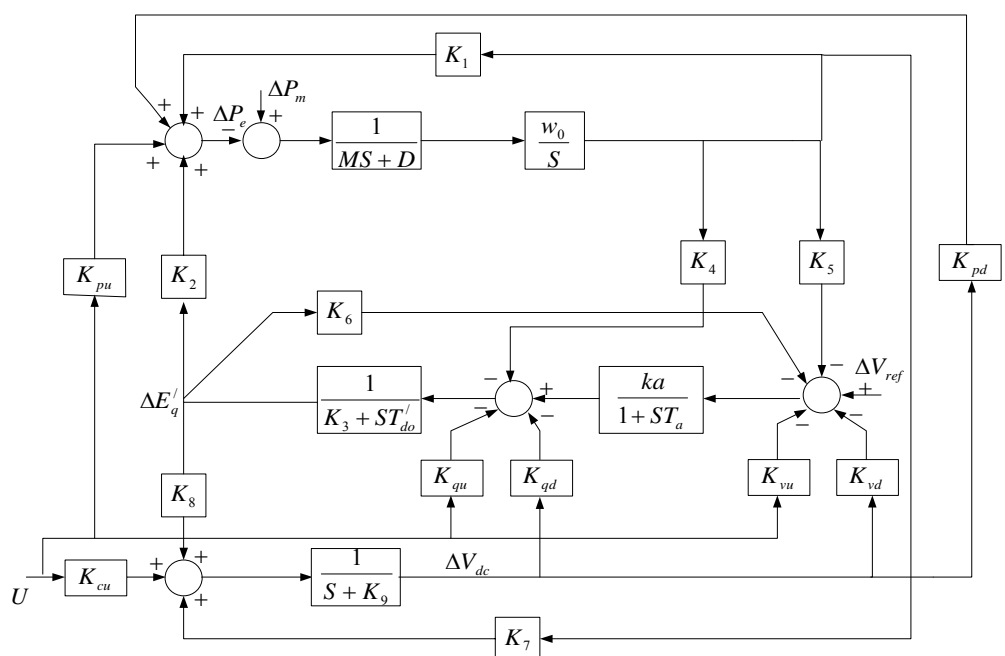

between the STATCOM and the power system is controlled.

It should be noted that $\mathrm{K}_{\mathrm{pu}}, \mathrm{K}_{\mathrm{qu}}, \mathrm{K}_{\mathrm{vu}}$ and $\mathrm{K}_{\mathrm{cu}}$ in Fig. 2 are the row vectors and defined as follows:

$\mathrm{K}_{\mathrm{pu}}=\left[\begin{array}{ll}\mathrm{K}_{\mathrm{pe}} & \mathrm{K}_{\mathrm{p} \delta \mathrm{e}}\end{array}\right] ; \mathrm{K}_{\mathrm{qu}}=\left[\begin{array}{ll}\mathrm{K}_{\mathrm{qe}} & \mathrm{K}_{\mathrm{q} \delta \mathrm{e}}\end{array}\right]$;

$\mathrm{K}_{\mathrm{vu}}=\left[\begin{array}{ll}\mathrm{K}_{\mathrm{ve}} & \mathrm{K}_{\mathrm{voe}}\end{array}\right] ; \mathrm{K}_{\mathrm{cu}}=\left[\begin{array}{ll}\mathrm{K}_{\mathrm{ce}} & \mathrm{K}_{\mathrm{c \delta e}}\end{array}\right]$

State space model

The dynamic model of the system in state-space form is obtained as (4).

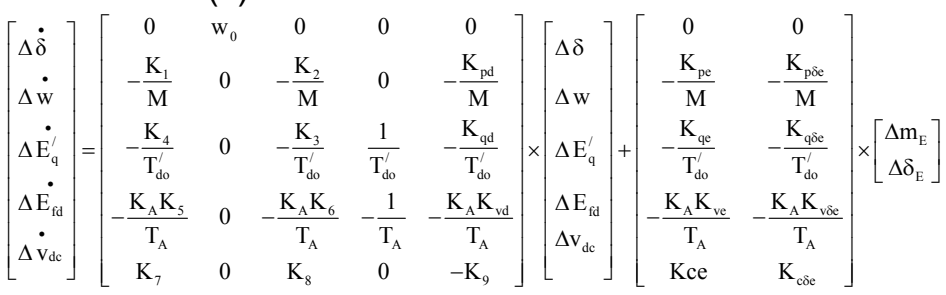


The typical values of system parameters for nominal operating condition are given in appendix.

\section{STATCOM Controllers}

The STATCOM control system comprises two controllers: DC-voltage regulator and Power system oscillation-

damping controller.

\section{$D C$-voltage regulator}

The STATCOM needs to a DC voltage regulator to regulate DC-link voltage. DC-voltage is regulated by modulating the phase angle of the shunt converter voltage. A P-I type controller is considered as voltage regulator here. The parameters of DC-voltage regulator are considered as follow for this research: $\mathrm{K}_{\mathrm{di}}=39.8$ and $\mathrm{K}_{\mathrm{dp}}=0.5778$.

\section{Supplementary stabilizer}

A stabilizer is provided to improve power system oscillations damping. This controller may be considered as a lead-lag compensator or the other methods. However an electrical torque in phase with the speed deviation must be produced in order to improve the

Fig. 3. The Structure of classical stabilizer

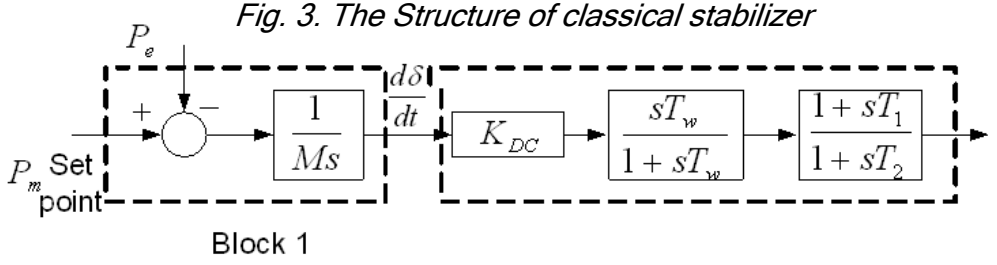

Block 1

damping of the system oscillation. The transfer function block diagram of the stabilizer is shown in Fig. 3.

\section{Eigen value analysis}

For the nominal operating condition the eigenvalues of the system are obtained using state-space model of the system presented in (4) and these eigenvalues are shown in Table 1. It is clearly seen that the system is unstable and needs to power system stabilizer (damping controller) for stability.

Stabilizer controllers design themselves have been a topic of interest for decades, especially in form of Power System Stabilizers (PSS). But PSS cannot control power transmission and also cannot support power system stability under large disturbances like 3-phase fault at terminals of generator. For these problems, in this paper a stabilizer controller based STATCOM is provided to mitigate power system oscillations. Two optimization methods such as PSO and GA are considered for tuning stabilizer controller parameters. In the next section an introduction about PSO is presented.

\section{Particle Swarm Optimization}

PSO was formulated by Edward and Kennedy in 1995. The thought process behind the algorithm was inspired by the social behavior of animals, such as bird flocking or fish schooling. PSO is similar to the continuous GA in that it begins with a random population matrix. Unlike the GA, PSO has no evolution operators such as crossover and mutation. The rows in the matrix are called particles (same as the GA chromosome). They
Vol. 4 No. 5 (May 2011)

ISSN: 0974- 6846 contain the variable values and are not binary encoded. Each particle moves about the cost surface with a velocity. The particles update their velocities and positions based on the local and global best solutions as shown in (5) and (6) (Randy et al., 2004):

$$
\begin{aligned}
& \mathrm{V}_{\mathrm{m}, \mathrm{n}}^{\text {new }}=\mathrm{w} \times \mathrm{V}_{\mathrm{m}, n^{\text {old }}}+\Gamma_{1} \times r_{1} \times\left(\mathrm{P}_{\mathrm{m}, \mathrm{n}}^{\text {local best }} \mathrm{P}_{\mathrm{m}, \mathrm{n}}^{\text {old }}\right)+ \\
& \Gamma_{2} \times r_{2} \times\left(P_{m, n} \text { global'best }-P_{m, n}{ }_{\text {old }}\right) \\
& P_{m, n}{ }^{\text {new }}=P_{m, n}{ }^{\text {old }}+\Gamma V_{m, n}^{\text {new }}
\end{aligned}
$$

Where:

$\mathrm{V}_{\mathrm{m}, \mathrm{n}}=$ particle velocity

$\mathrm{P}_{\mathrm{m}, \mathrm{n}}=$ particle variables

$\mathrm{W}=$ inertia weight

$r_{1}, r_{2}=$ independent uniform random numbers

$\Gamma_{1}=\Gamma_{2}=$ learning factors

$\mathrm{P}_{\mathrm{m}, \mathrm{n}}$ local best $=$ best local solution

$P_{m, n}{ }^{\text {global best }}=$ best global solution

The PSO algorithm updates the velocity vector for each particle then adds that velocity to the particle position or values. Velocity updates are influenced by both the best global solution associated with the lowest cost ever found by a particle and the best local solution associated with the lowest cost in the present population. If the best local solution has a cost less than the cost of the current global solution, then the best local solution replaces the best global solution. The particle velocity is reminiscent of local minimizes that use derivative information, because velocity is the derivative of position. The advantages of PSO are that it is easy to implement and there are few parameters to adjust. The PSO is able to tackle tough cost functions with many local minima (Randy et al., 2004). PSO based stabilizer

In this section the parameters of the proposed stabilizer controller are tuned using PSO. Two control parameters of the STATCOM $\left(m_{E}\right.$ and $\left.\delta_{E}\right)$ can be modulated in order to produce the damping torque. The parameter $m_{E}$ is modulated to output of stabilizer and speed deviation $\Delta \omega$ is also considered as input of stabilizer. The structure of supplementary stabilizer controller has been shown in Fig. 3. The parameters in Fig. 3 are as follow:

$\mathrm{K}_{\mathrm{DC}}$ : the stabilizer gain

$\mathrm{T}_{\mathrm{W}}$ : the parameter of washout block

$T_{1}$ and $T_{2}$ : the parameters of compensation block

The optimum values of $K_{D C}, T_{1}$ and $T_{2}$ which minimize an array of different performance indexes are accurately computed using PSO and $T_{W}$ is considered equal to 10. In optimization methods, the first step is to define a performance index for optimal search. In this study the performance index is considered as (7). In fact, the performance index is the Integral of the Time multiplied Absolute value of the Error (/TAE).
"Stabilizer design based on STATCOM" http://www.indjst.org
Reza Hemmati et al. Indian J.Sci.Technol. 


$$
\text { ITAE }=\int_{0}^{\mathrm{t}} \mathrm{t}|\Delta \omega| \mathrm{dt}+\int_{0}^{\mathrm{t}} \mathrm{t}\left|\Delta \mathrm{V}_{\text {DC }}\right| \mathrm{dt}
$$

Where, $\Delta \omega$ is the frequency deviation, $\Delta V_{D C}$ is the deviation of DC voltage and parameter "t" in ITAE is the simulation time. In this paper a 100 seconds time period is considered for simulation. It is clear to understand that the controller with lower ITAE is better than the other controllers. To compute the optimum parameter values, a 0.1 step change in mechanical torque $(\Delta \mathrm{Tm})$ is assumed and the performance index is minimized using PSO. In order to acquire better performance, number of particle, particle size, number of iteration, $\Gamma_{1}, \Gamma_{2}$, and $\Gamma$ are chosen as 24 , $3,50,2,2$ and 1, respectively. Also, the inertia weight, w, is linearly decreasing from 0.9 to 0.4 . The optimum values of $\mathrm{K}_{\mathrm{DC}}, \mathrm{T}_{1}$ and $\mathrm{T}_{2}$, resulting from minimizing the performance index is presented in Table 2. Also in order to show effectiveness of PSO method, the parameters of stabilizer controller are tuned using the other optimization method, GA. In GA case, the performance index is considered as PSO case and the optimal parameters of stabilizer controller are obtained as shown in Table 3. In this paper the boundaries of optimal search for parameters are as follows:

1回 $\mathrm{K}_{\mathrm{DC}}$ 回 1000; 0.01国 $\mathrm{T}_{1}$ 回 $1 ; 0.01$ 回 $\mathrm{T}_{2}$ 回1

\section{Simulation results}

In this section, the designed PSO and GA based stabilizers are applied to system in order to damping low frequency oscillations. In order to study and analysis system performance under system uncertainties (controller robustness), two operating conditions are considered as follow:

Case 1: Nominal operating condition

Case 2: Heavy operating condition

Table 4. 10\% Step increase in the reference mechanical torque $\left(\Delta T_{m}\right)$

\begin{tabular}{|l|l|l|}
\hline \multirow{2}{*}{} & \multicolumn{2}{|c|}{ The calculated ITAE } \\
\cline { 2 - 3 } & PSO Stabilizer & GA Stabilizer \\
\hline Nominal operating condition & 0.0021 & 0.0023 \\
\hline Heavy operating condition & 0.0026 & 0.0031 \\
\hline
\end{tabular}

The parameters for two cases are presented in appendix. PSO and GA stabilizer controllers have been designed for the nominal operating condition. In order to demonstrate the robustness performance of the proposed method, The ITAE is calculated following $10 \%$ step change in the reference mechanical torque $\left(\Delta T_{m}\right)$ at all operating conditions (Nominal and Heavy) and results are shown in Table 4. Following step change, the PSO based stabilizer has better performance than the GA based stabilizer at all operating conditions.

Also for case 1, the simulation results (Fig. 4) show that applying the supplementary control signal greatly enhances the damping of the generator angle oscillations and therefore the system becomes more stable. The PSO
Vol. 4 No. 5 (May 2011)

ISSN: 0974- 6846

stabilizer performs better than the GA controller. For case 2, the simulation results are shown in Fig. 5. Under this condition, while the performance of GA supplementary controller becomes poor, the PSO controller has a stable and robust performance. It can be concluded that the PSO supplementary controller have suitable parameter adaptation in comparing with the GA supplementary controller when operating condition changes.

\section{Conclusions}

0.481 0.2

In this paper Genetic Algorithms and Particle Swarm Optimization have been successfully applied to design stabilizer controller based STATCOM. A Single Machine Infinite Bus power system installed with a STATCOM with various load conditions has been assumed to demonstrate the methods. Simulation results
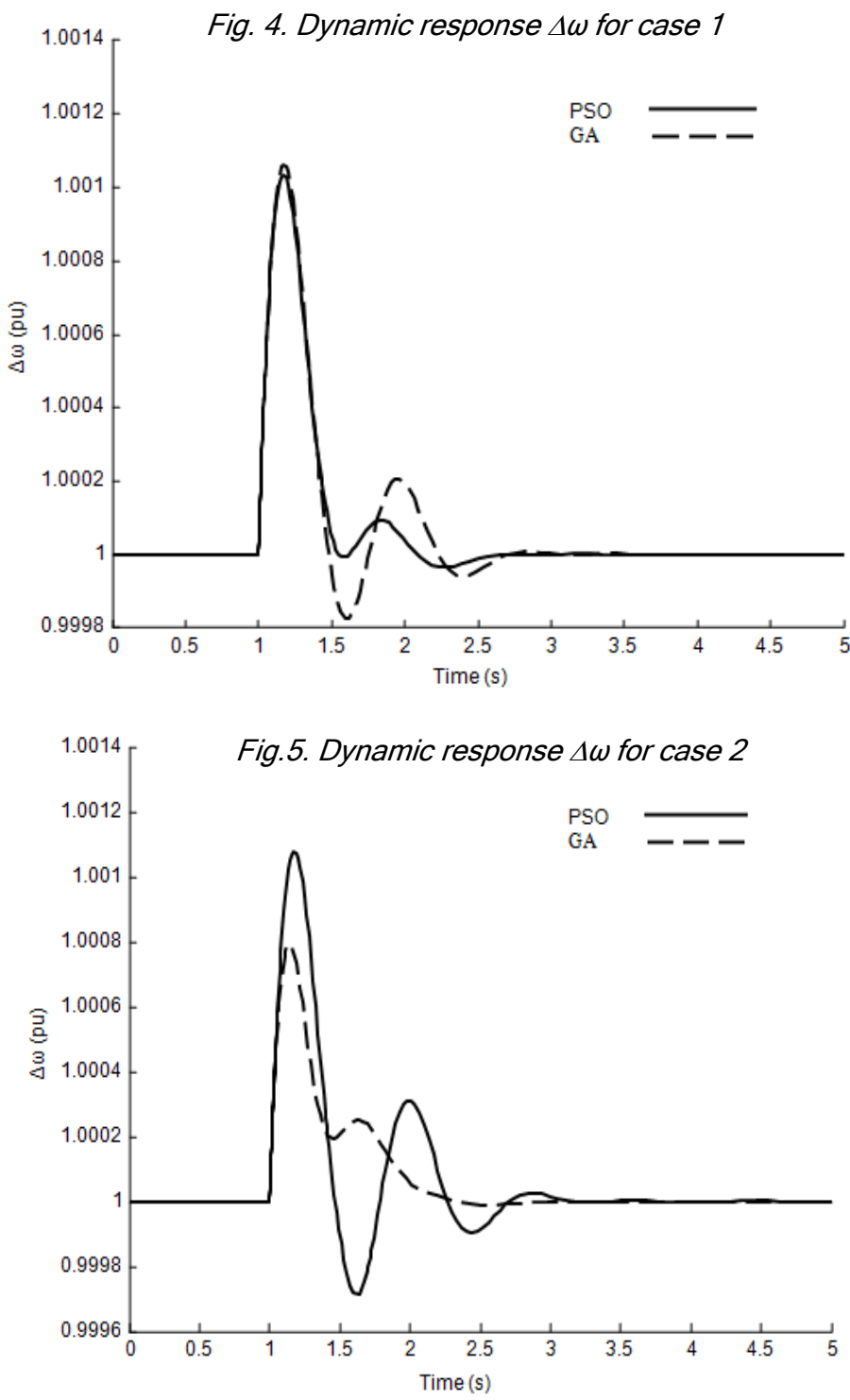

Research article

CIndian Society for Education and Environment (iSee)
"Stabilizer design based on STATCOM" http://www.indjst.org
Reza Hemmati et al. Indian J.Sci.Technol. 
Indian Journal of Science and Technology

Table 5. System parameters

\begin{tabular}{|l|l|l|l|}
\hline Generator & $\mathrm{M}=8 \mathrm{Mj} / \mathrm{MVA}$ & $\mathrm{T}^{\prime}{ }_{\text {do }}=5.044 \mathrm{~s}$ & $\mathrm{X}_{\mathrm{d}}=1 \mathrm{p} . \mathrm{u}$. \\
\hline Excitation system & $\mathrm{X}_{\mathrm{q}}=0.6 \mathrm{p} . \mathrm{u}$. & $\mathrm{X}^{\prime} \mathrm{d}=0.3 \mathrm{p} . \mathrm{u}$. & $\mathrm{D}=0$ \\
\hline Transformers & & $\mathrm{K}_{\mathrm{a}}=10$ & $\mathrm{~T}_{\mathrm{a}}=0.05 \mathrm{~s}$ \\
\hline Transmission lines & & $\mathrm{X}_{\mathrm{te}}=0.1 \mathrm{p} . \mathrm{u}$. & $\mathrm{X}_{\mathrm{SDT}}=0.1 \mathrm{p} . \mathrm{u}$. \\
\hline DC link parameters & & $\mathrm{X}_{\mathrm{T} 1}=1$ p.u. & $\mathrm{X}_{\mathrm{T} 2}=1.25 \mathrm{p} . \mathrm{u}$. \\
\hline STATCOM parameters & & $\mathrm{V}_{\mathrm{DC}}=2$ p.u. & $\mathrm{C}_{\mathrm{DC}}=3 \mathrm{p} . \mathrm{u}$. \\
\hline
\end{tabular}

demonstrated that the designed controllers capable to guarantee the robust stability and robust performance under a different load conditions. Also, simulation results show that the PSO method has an excellent capability in power system oscillations damping and power system stability enhancement under small disturbances in comparison with GA method.

Table 6. System operating conditions

\begin{tabular}{|l|l|l|l|}
\hline Operating condition 1 & $\mathrm{P}=1$ p.u. & $\mathrm{Q}=0.2$ p.u. & $\mathrm{V}_{\mathrm{t}}=1.03$ p.u. \\
\hline Operating condition 2 & $\mathrm{P}=1.1$ p.u. & $\mathrm{Q}=0.35$ p.u. & $\mathrm{V}_{\mathrm{t}}=1.03$ p.u. \\
\hline
\end{tabular}

\section{Appendix}

The nominal parameters and nominal operating condition of the system are listed in Table 5. Also system operating conditions are defined as Table 6 (Operating condition 1 is the nominal operating condition).

\section{References}

1. Ainsworth JD, Davies M, Fitz JB, Owen KE and Trainer DR (1998) Static Var compensator (STATCOM) based on single-phase chain circuit converters. IEE Proc. Generation, Trans. \& Distribution. 145 (4), 381-386.

2. Al-Awami AT (2007) A particle-swarm-based approach of power system stability enhancement with UPFC. Electrical Power \& Energy Systems. 29, 251259.

3. Cheng S, Malik OP and Hope SG (1986) Self-Tuning stabilizers for a multi-machine power system. IEE Proc. Part C (4), 176-185.

4. Ekanayake JB, Jenkins $\mathrm{N}$ and Cooper CB (1995) Experimental investigation of an advanced static Var Compensator. IEE Proc. Generation, Trans. \& Distribution. 142 (2), 202-210.

5. Eldamaty AA, Faried SO and Aboreshaid S (2005) Damping power system oscillation using a fuzzy logic based unified power flow controller. IEEE CCECE/CCGEI. 1, 1950-1953.

6. Gyugyi L (1979) Reactive power generation and control by Thyristor circuits. IEEE Trans. IA-15 (5), 521-532.

7. Gyugyi L, Hingorani NG, Nannery PR and Tai $T$ (1990) Advanced static Var compensator using gate turn-off Thyristors for utility applications. In: Proc. of the 1990 CIGRE Conf. 23-203.
Vol. 4 No. 5 (May 2011)

ISSN: 0974- 6846

8. Heffron WG and Phillips RA (1952) Effect of a modem amplidyne voltage regulator on under excited operation of large turbine generator. AlEE Trans. 71-80.

9. Hingorani NG and Gyugyi L (2000) Understanding FACTS. IEEE Press. New York.

10. Mishra S, Dash PK and Panda G (2000) TSFuzzy controller for UPFC in a multi-machine power system. IEE Proc. on Generation, Transmission \& Distribution. 147 (1), 15-22.

11. Mori S, Matsuno K, Takeda M and Seto M (1993) Development of a large static Var generator using self-commutated inverters for improving power system stability. IEEE Trans. Power System.

12. Randy LH and Sue EH (2004) Practical genetic algorithms. John Wiley \& Sons, $2^{\text {nd }}$ Edition.

13. Saad-Saoud Z, Lisboa ML, Kanayake JBE, Jenkins N and Strbac G (1998) Application of STATCOMs to wind Farms. IEE Proc. Generation, Trans. \& Distribution. 145 (5), 511-516.

14. Schauder C and Mehta AH (1993) Vector analysis and control of advanced static VAR compensator. In: Proc. of the IEE Conf. 299-306.

15. Schauder C, Gernhardt M, Stacey E, Cease TW and Edrise A (1995) Development of a \pm 100 MVAR static condenser for voltage control of transmission systems. IEEE Trans on Power Delivery. 10 (3), 1486-1496.

16. Tambey $N$ and Kothari ML (2003) Damping of power system oscillation with unified power flow controller (UPFC). IEE Proc. Generation, Trans. \& Distribution. 150 (2), 129-140.

17. Trainner DR, Tennakoon SB and Morrison RE (1994) Analysis of GTO-Based static VAR compensators. IEE Proc. Generation, Trans. \& Distribution. 141 (6), 293-302.

18. Wang HF (1999) Phillips-Heffron model of power systems installed with STATCOM and applications. IEE Proc. Generation, Trans. \& Distribution. 146 (5), 521-527.
"Stabilizer design based on STATCOM" http://www.indjst.org
Reza Hemmati et al. Indian J.Sci.Technol. 